\title{
Casitas B-lineage lymphoma linker helix mutations found in myeloproliferative neoplasms affect conformation
}

\author{
Lori Buetow ${ }^{1}$, Giancarlo Tria ${ }^{2,4}$, Syed Feroj Ahmed', Andreas Hock1, Hao Dou ${ }^{1,3}$, Gary J. Sibbet',
} Dmitri I. Svergun ${ }^{2}$ and Danny T. Huang ${ }^{1 *}$

\begin{abstract}
Background: Casitas B-lineage lymphoma (Cbl or c-Cbl) is a RING ubiquitin ligase that negatively regulates protein tyrosine kinase (PTK) signalling. Phosphorylation of a conserved residue (Tyr371) on the linker helix region (LHR) between the substrate-binding and RING domains is required to ubiquitinate PTKs, thereby flagging them for degradation. This conserved Tyr is a mutational hotspot in myeloproliferative neoplasms. Previous studies have revealed that select point mutations in Tyr371 can potentiate transformation in cells and mice but not all possible mutations do so. To trigger oncogenic potential, Cbl Tyr371 mutants must perturb the LHR-substrate-binding domain interaction and eliminate PTK ubiquitination. Although structures of native and pTyr371-Cbl are available, they do not reveal how Tyr371 mutations affect Cbl's conformation. Here, we investigate how Tyr371 mutations affect Cbl's conformation in solution and how this relates to Cbl's ability to potentiate transformation in cells.

Results: To explore how Tyr371 mutations affect Cbl's properties, we used surface plasmon resonance to measure Cbl mutant binding affinities for E2 conjugated with ubiquitin (E2-Ub), small angle X-ray scattering studies to investigate $\mathrm{Cbl}$ mutant conformation in solution and focus formation assays to assay $\mathrm{Cbl}$ mutant transformation potential in cells. Cbl Tyr371 mutants enhance E2-Ub binding and cause Cbl to adopt extended conformations in solution. LHR flexibility, RING domain accessibility and transformation potential are associated with the extent of LHR-substrate-binding domain perturbation affected by the chemical nature of the mutation. More disruptive mutants like $\mathrm{Cbl}$ Y371D or Y371S are more extended and the RING domain is more accessible, whereas CbI Y371F mimics native $\mathrm{Cbl}$ in solution. Correspondingly, the only Tyr371 mutants that potentiate transformation in cells are those that perturb the LHR-substrate-binding domain interaction.
\end{abstract}

Conclusions: $\mathrm{c}-\mathrm{Cb}$ 's LHR mutations are only oncogenic when they disrupt the native state and fail to ubiquitinate PTKs. These findings provide new insights into how LHR mutations deregulate c-Cbl.

Keywords: Ubiquitin, Cbl, Myeloproliferative neoplasms, SAXS, Transformation potential

Abbreviations: Cbl, Casitas B-lymphoma lineage; $D_{\max }$ Maximum particle distance; E2 Ub, E2 conjugated to ubiquitin via a thioester; EOM, Ensemble optimization method; GA, Genetic algorithm; GST, Glutathione S-transferase; LH, Linker helix; LHR, Linker helix region; LL1, Linker loop 1; LL2, Linker loop 2; MDS/MPN, Myelodysplastic syndromes-myeloproliferative neoplasms; MM, Molecular mass; N-Cbl, N-terminal fragment of Cbl comprising residues 47-435; PTK, Protein tyrosine kinase; $R_{\text {flex }}$ Quantification of protein flexibility estimated by EOM; $R_{\mathrm{g}}$, Radius of gyration; SAXS, Small angle X-ray scattering; SPR, Surface plasmon resonance; TK, Tyrosine kinase; TKBD, Tyrosine kinase binding domain; Ub, Ubiquitin; UbcH5B-Ub, Ubiquitin stably conjugated to UbcH5B via an isopeptide bond; WT, Wild-type

\footnotetext{
* Correspondence: d.huang@beatson.gla.ac.uk

${ }^{1}$ Cancer Research UK Beatson Institute, Garscube Estate, Switchback Road,

Glasgow G61 1BD, UK

Full list of author information is available at the end of the article
} 


\section{Background}

Dysregulated signalling is a prominent feature in cellular transformation and tumorigenesis. The proto-oncogene Casitas B-lineage lymphoma ( $\mathrm{Cbl}$ or $\mathrm{c}-\mathrm{Cbl}$ ), encodes an E3 ubiquitin ligase that downregulates PTK-directed cell signaling through ubiquitination, thereby targeting these kinases for lysosomal or proteasomal degradation $[1,2]$. $\mathrm{Cbl}$ is a member of the $\mathrm{Cbl}$ family of proteins, so characterized based on a highly conserved $\mathrm{N}$-terminal region that contains the structural components required for ubiquitin ligase activity. In simpler eukaryotic organisms, such as Caenorhabditis elegans and Dictyostelium discoideum, only one Cbl protein is present, but in mammals there are three, including $\mathrm{Cbl}, \mathrm{Cbl}-\mathrm{b}$ and $\mathrm{Cbl}-\mathrm{c}$.

The conserved N-terminus of $\mathrm{Cbl}$ family proteins contains a substrate tyrosine kinase-binding domain (TKBD), a linker helix region (LHR) and a RING domain (Fig. 1a). The TKBD confers specificity to Cbl's ligase activity based on the selective recruitment of phosphorylated substrates containing an (N/D)XpY(S/T)XXP, DpYR or RA(V/I)XNQpY(S/T) motif [3]. The RING domain mediates the transfer of ubiquitin (Ub) from an E2 Ub-conjugating

a

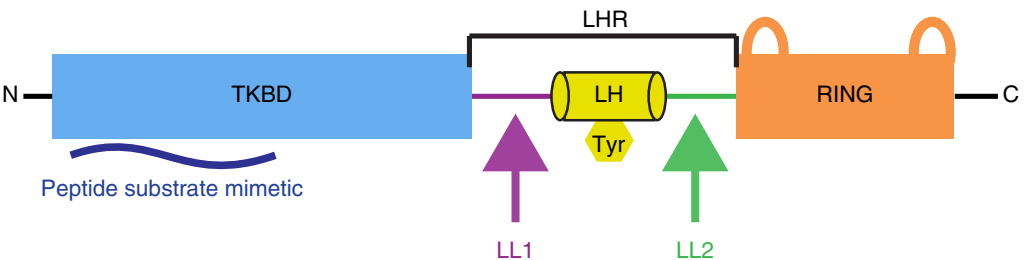

b

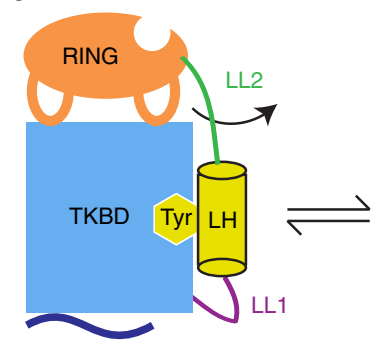

Native unphosphorylated closed \& autoinhibited
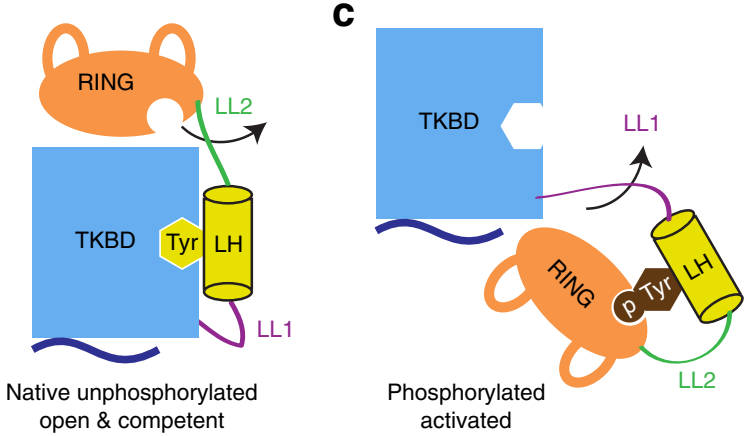

d
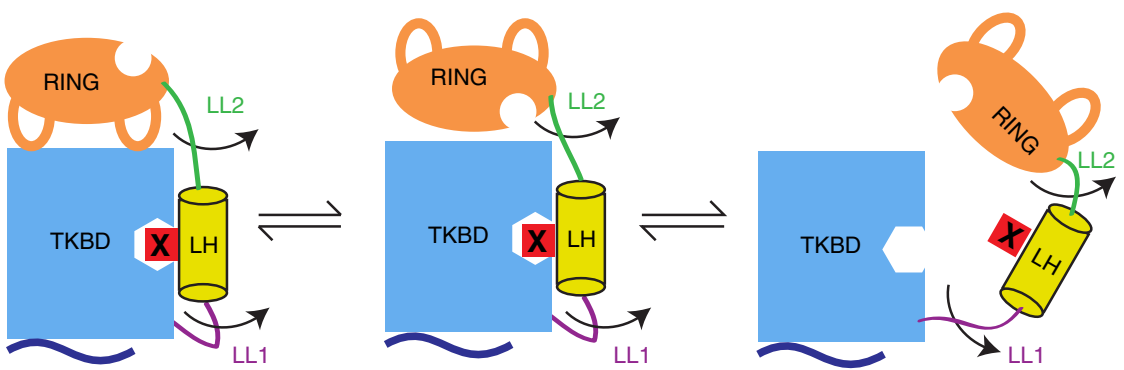

LH Tyr371 mutant closed \& autoinhibited

LH Tyr371 mutant open \& competent

LH Tyr371 mutant

unlocked \& intermediate activity

Fig. 1 Model depicting linker helix (LH)-mediated regulation of Cbl ligase. a Domains of Cbl's N-terminal ubiquitin ligase region. A blue rectangle and navy wavy line correspondingly depict the TKBD and its substrate-binding site. The LHR and its components are indicated with LL1 coloured purple, LL2 green and LH yellow. A yellow hexagon depicts the LH Tyr. The RING is coloured orange with the two loops representing the E2binding site. $\mathbf{b}$ Model of unphosphorylated Cbl coloured as in (a). When Tyr371 is unphosphorylated, the LH is clamped to the TKBD and movement of the RING restricted to the TKBD face opposing the substrate-binding site. Rotation about LL2 allows Cbl to fluctuate between an autoinhibited state where the E2-binding site is occluded (left) and a catalytically competent state where E2 is able to bind (right). c Model of phosphorylated Cbl coloured as in (a). A brown hexagon and circle represent the phosphorylated LH Tyr. When Tyr371 is phosphorylated, the $\mathrm{LH}$ clamps into the RING domain and LL1 rotates $180^{\circ}$, juxtaposing the RING domain and substrate-binding face of the TKBD. The Tyr371 binding site on the TKBD cannot accommodate a phosphate moiety, thereby eliminating the LH-TKBD interaction. Whether the RING domain is flexible in solution is unknown. d Model depicting possible states of Cbl Tyr 371 mutants coloured as in (a). The LH Tyr371 mutant is shown as an X in a red square. Cbl Y371X mutants are predicted to favour different states depending on the chemical nature of the substitution. Less disruptive mutants are expected to maintain the unphosphorylated equilibrium (left and middle), whereas more disruptive mutants are expected to perturb the LH-TKBD interaction, leaving the RING in an open, catalytically competent conformation with greater access to space surrounding the TKBD (right) 
enzyme to the substrate $[4,5]$. Within the LHR is a conserved tyrosine (Tyr371 in Cbl) that is crucial for regulating ligase activity. Phosphorylation of this tyrosine enhances ligase activity and is essential for ubiquitination of receptor PTKs [6-11]. In addition to the highly conserved $\mathrm{N}$-terminus, $\mathrm{Cbl}$ and $\mathrm{Cbl}-\mathrm{b}$ also have extensive $\mathrm{C}$-termini that confer adaptor-like functions to these proteins based on the ability to mediate multiple protein-protein interactions. These include a proline rich region that mediates interactions with $\mathrm{SH} 3$ domain-containing proteins and a tyrosine rich region that, upon phosphorylation, becomes a binding motif for other SH2 domain-containing proteins [12]. Cbl and Cbl-b terminate with an ubiquitin-associated domain, which is crucial for homo- and heterodimerization of these two Cbl proteins [13, 14].

$\mathrm{Cbl}$ abnormalities are associated with a number of human cancers. High expression of $\mathrm{Cbl}$ is commonly observed in several human breast cancer cell lines as well as primary breast and prostate cancer tissues $[15,16]$. In addition, $\mathrm{Cbl}$ mutations are observed in myelodysplastic syndromes-myeloproliferative neoplasms (MDS/MPN) and non-small cell lung cancers $[17,18]$. Cbl is suggested to have different roles in pathological processes depending on its function as a ligase or adaptor. Breast and prostate cancer cell line oncogenic characteristics are reduced when $\mathrm{Cbl}$ is knocked down, and, in breast cancer cells, independent of its ligase activity, $\mathrm{Cbl}$ mediates suppression of transcriptional activity induced by the tumour suppressor transforming growth factor- $\beta 1[15,16]$. In contrast, more in-depth studies of select MDS/MPN mutants suggest that these mutants potentiate transformation because they fail to ubiquitinate and thereby downregulate PTK signalling $[19,20]$.

The highest frequency of missense mutations in MDS/ MPN clinical samples occurs at Tyr371; identified mutations include Cbl Y371S, Y371H, Y371C, and Y371D. Cbl $\mathrm{Y} 371 \mathrm{~S}$ and $\mathrm{Y} 371 \mathrm{H}$ have been investigated extensively in independent studies $[19,20]$. Cbl Y371S promotes colony formation in soft-agar assays and induces tumour formation when injected into nude mice. Likewise, Cbl Y371H promotes cytokine-independent growth in cells but only when endogenous $\mathrm{Cbl}$ is knocked down. Both display defects in their ability to ubiquitinate the PTK EGFR. For Tyr371 mutations in the LHR, although defective PTK ubiquitination contributes to aberrant cell signalling, it is not sufficient to potentiate transformation. Cbl Y371F shows reduced EGFR ubiquitination in vitro and in cells $[6,21]$, but it is significantly less efficient in promoting colony formation in soft agar assays and does not induce tumour formation when injected into mice $[21,22]$.

A number of factors contribute to how phosphorylation of Tyr371 regulates Cbl's ligase activity. In the unphosphorylated state, Cbl's RING domain rotates between an open, catalytically competent conformation and a closed conformation (Fig. 1b) [5, 6]. In the closed conformation, the E2-binding site on the RING domain is occluded and $\mathrm{Cbl}$ is autoinhibited. Although the RING can bind E2 thioesterified with Ub (E2 Ub; indicates thioester bond) in the unphosphorylated state, the RING domain is restricted to the TKBD face opposite the substrate-binding site by interactions between the LHR and TKBD. The LHR comprises a long loop (called linker loop 1 or LL1, residues 353-363) followed by an $\alpha$-helix (LH, residues 364-374) and then a second shorter loop (LL2, residues 375-380). Tyr371 is on the $\mathrm{LH}$, and, in the unphosphorylated state, Tyr371 and several other residues from the LH, including Tyr368, bind to the TKBD, limiting movement between the RING and TKBD to rotation about LL2. Phosphorylation of Tyr371 eliminates this LHR-TKBD interaction - modelling suggests the Tyr371 binding pocket on the TKBD is too small to accommodate a phosphate group. Instead, pTyr371-LHR forms a new set of interactions with the RING domain that stabilizes E2 $\sim$ Ub during Ub transfer $[6,7]$. Movement within LL2 is more restricted by this new set of interactions but a conformational change in LL1 juxtaposes the RING domain with the substrate-binding face of the TKBD (Fig. 1c). In solution, whether LL1 is flexible and adopts multiple conformations or prefers the crystallographically observed conformation where the RING is juxtaposed with the substrate binding face of the TKBD is unclear.

We postulate that Y371 mutations might have different oncogenic potentials due to flexibility differences in Cbl's linker region mediated by the LHR-TKBD interaction (Fig. 1d). We predict that, while a large aromatic residue like Phe cannot duplicate the Tyr371-TKBD interactions, neither will it perturb those interactions; hence, Cbl Y371F can adopt and readily maintain conformations observed in the unphosphorylated state. On the other hand, mutations, such as Y371S, introduce a polar residue into a hydrophobic pocket and are likely to perturb or occlude the LH-TKBD interaction, thereby unlocking the LHR from the TKBD and leaving $\mathrm{Cbl}$ in an intermediate activity state where the E2 $\sim \mathrm{Ub}$ binding site on the RING domain is exposed but lacking the pTyr371-LHR E2 Ub stabilizing component (Fig. 1c,d). To investigate the influence of mutations and phosphorylation on Cbl's LHR flexibility and RING accessibility in solution, we performed small-angle X-ray scattering (SAXS) analysis and surface plasmon resonance (SPR) assays on pTyr371-Cbl, unphosphorylated $\mathrm{Cbl}$ and a selection of $\mathrm{Cbl}$ variants. We then performed focus formation assays to explore the relationship between this flexibility and oncogenic potential. 


\section{Results}

\section{Cbl's LHR-TKBD interactions affect RING binding affinity} for E2 Ub

Previous studies suggest Cbl Y371 mutants have the potential to perturb or abrogate LHR-E2 interactions essential for ligase activity $[5,21]$. To investigate this possibility, we used SPR to measure binding of the substrate E2 UbcH5B conjugated to $\mathrm{Ub}$ (UbcH5B-Ub; hyphen indicates a non-hydrolyzable amide linkage) to variants of the $\mathrm{N}$-terminal fragment of $\mathrm{Cbl}$ comprising the TKBD, linker region and RING domain $(\mathrm{N}-\mathrm{Cbl}$, residues 47-435), as performed previously [6, 23]. We tested the unphosphorylated $\mathrm{N}-\mathrm{Cbl}$ variants containing the Tyr371 mutations identified in MDS/MPN clinical samples as well as N-Cbl Y371A, which behaves similarly to the MDS/MPN Tyr371 mutants [21], and N-Cbl Y371F based on its reduced transformation potential in cells and mice. In addition, we tested $\mathrm{Cbl}$ Y371E, which has previously been shown to stimulate Cbl activity in vitro [8]. $\mathrm{N}-\mathrm{Cbl} \mathrm{Y368F}$ was also included in our assays because this mutation is required to generate homogeneously phosphorylated pTyr371-N-Cbl; previous studies demonstrate this mutation does not affect the structure or ligase activity in vitro or in cells $[6,21,22]$. We also included N-Cbl M222E, which disrupts the closed conformation without perturbing the TKDB-LHR interaction [6], so that we could investigate changes induced by rotation about LL2. We predicted that, if the RING domain were unfolded, no binding of UbcH5B-Ub to N-Cbl Y371 variants is expected, whereas, if these variants simply weaken the LHR-TKBD interaction, Cbl Y371 mutants will adopt the closed conformation less frequently and thus bind UbcH5B-Ub more tightly than wild-type $\mathrm{N}$ Cbl. None of the N-Cbl Y371 mutants is expected to bind UbcH5B-Ub as tightly as pTyr371-N-Cbl because pTyr371 eliminates the closed, autoinhibited conformation and forms additional interactions with $\mathrm{UbcH} 5 \mathrm{~B} \sim \mathrm{Ub}$. All of the $\mathrm{N}-\mathrm{Cbl}$ variants in our SPR assay bind UbcH5B-Ub with similar or higher affinity than wildtype $\mathrm{N}-\mathrm{Cbl}(84 \mu \mathrm{M})$ but more weakly than pTyr371$\mathrm{N}-\mathrm{Cbl}(2.6 \mu \mathrm{M}$, Table 1), suggesting mutations in the LHR do not affect the competency of the RING domain to bind UbcH5B-Ub. Other mutations in the LHR also affect LHR-TKBD interactions as evidenced by the higher binding affinity of N-Cbl Y368F $(49 \mu \mathrm{M})$ for UbcH5B-Ub than wild-type N-Cbl.

The SPR data demonstrate that the chemical characteristics of the side chain of the mutated amino acid in the $\mathrm{N}-\mathrm{Cbl} \mathrm{Y} 371$ variants influence binding affinity for $\mathrm{UbcH} 5 \mathrm{~B}-\mathrm{Ub}$ : the greater potential the mutation has to perturb the Tyr371 binding pocket on the TKBD, the higher the binding affinity for UbcH5B-Ub. The highest binding affinities are observed when Tyr is substituted with an amino acid that has a shorter, non-aromatic and
Table 1 Dissociation constants $\left(K_{\mathrm{d}}\right)$ for interactions between $\mathrm{Cbl}$ variants and $\mathrm{UbcH} 5 \mathrm{~B}-\mathrm{Ub}$

\begin{tabular}{llc}
\hline Immobilized GST-Cbl variant & Analyte & $K_{d}(\mu M)$ \\
\hline WT & UbcH5B-Ub & $84 \pm 2$ \\
Y371F & UbcH5B-Ub & $84 \pm 2$ \\
Y371H & UbcH5B-Ub & $39 \pm 1$ \\
Y371C & UbcH5B-Ub & $36 \pm 1$ \\
Y371A & UbcH5B-Ub & $30 \pm 1$ \\
Y371S & UbcH5B-Ub & $16 \pm 0.7$ \\
Y371D & UbcH5B-Ub & $10 \pm 0.5$ \\
Y371E & UbcH5B-Ub & $9 \pm 0.4$ \\
PY371 Y368F & UbcH5B-Ub & $2.6 \pm 0.6$ \\
Y368F & UbcH5B-Ub & $49 \pm 2$ \\
M222E & UbcH5B-Ub & $14 \pm 0.6$ \\
\hline
\end{tabular}

Standard errors of the mean are indicated

polar or charged side chain like N-Cbl Y371S $(16 \mu \mathrm{M})$, Y371E $(9 \mu \mathrm{M})$, and Y371D $(10 \mu \mathrm{M})$; the binding affinities of these mutants are comparable to N-Cbl M222E $(14 \mu \mathrm{M})$, which disrupts the RING-TKBD interaction in the closed, autoinhibited conformation. In contrast, when Tyr371 is substituted with Phe, the UbcH5B-Ub binding affinity is comparable to wild-type (N-Cbl Y371F, $84 \mu \mathrm{M})$ and the LHR-TKBD interaction is unperturbed, as demonstrated by the crystallographic structure of N-Cbl Y371F (Additional file 1: Figure S1, Table S1). For the remaining MDS/MPN mutants, polar and aromatic or short and hydrophobic amino acids are substituted for Tyr371 (NCbl Y371H, Y371A and Y371C). These are expected to weaken the interactions within the Tyr371 binding pocket but not as effectively as the group of mutants with short and polar or charged side chains. Thus, the UbcH5B-Ub binding affinity of these mutants is expected to fall between wild-type and the more disruptive mutants and this is indeed what we observe in our SPR assays: N-Cbl Y371H $(39 \mu \mathrm{M}), \mathrm{Y} 371 \mathrm{~A}(30 \mu \mathrm{M})$ and Y371C $(36 \mu \mathrm{M})$.

\section{Characterization of wild-type and pTyr371 CbI by SAXS}

Initially, we sought to investigate how Tyr371 phosphorylation affects the conformation of $\mathrm{Cbl}$ in solution by performing SAXS analysis on pTyr371-N-Cbl and wild-type $\mathrm{N}$-Cbl. The monomeric state of these $\mathrm{N}-\mathrm{Cbl}$ variants was confirmed by the SAXS-derived overall parameters (Fig. 2, Table 2, Additional file 1: Table S2) and gel filtration chromatography (data not shown). The deduced molecular masses (MMs) ranged from 41 to $48 \mathrm{kDa}$ and are comparable with a predicted monomer mass of $\sim 45 \mathrm{kDa}$ for $\mathrm{N}-\mathrm{Cbl}$.

The SAXS-derived radius of gyration $\left(R_{\mathrm{g}}\right)$ of wild-type $\mathrm{N}-\mathrm{Cbl}$ variant is $\sim 2.4 \mathrm{~nm}$ whereas pTyr371-N-Cbl is $\sim 2.8 \mathrm{~nm}$, and the calculated maximum particle distances $\left(D_{\max }\right)$ are $\sim 7.0$ and $\sim 9.2 \mathrm{~nm}$, respectively. These differences 


\section{a}

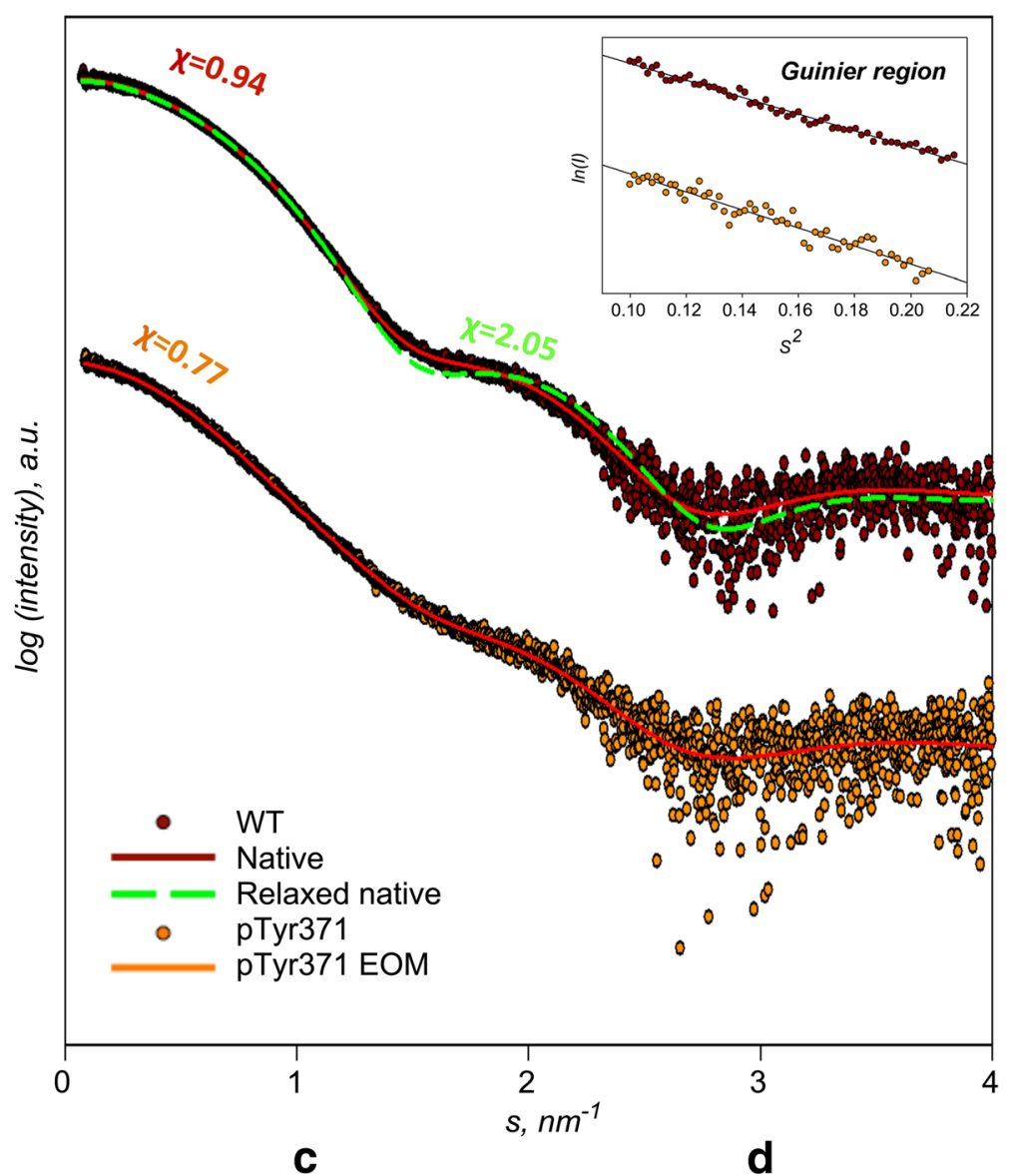

b

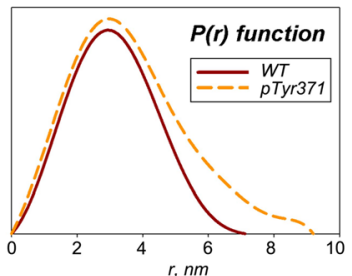

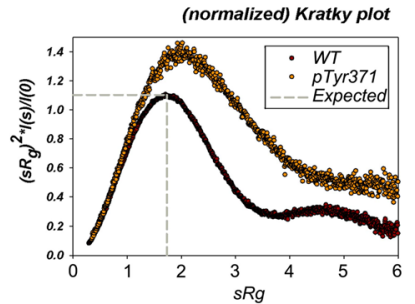

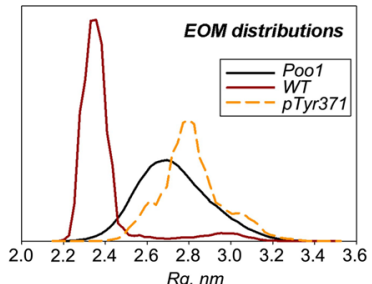

Fig. 2 SAXS analysis of wild-type (WT) and pTyr371-N-Cbl. a Top: WT experimental scattering data (dark red) versus theoretical scattering curve from crystal structure (PDB:2Y1M) before (dashed green line; $X=2.05)$ and after normal modes refinement (solid red line; $X=0.94)$. Bottom: pTyr371-N-Cbl experimental scattering data (orange) versus theoretical scattering from the EOM 2.0 ensemble (orange line; $X=0.77$ ). b $P(r)$ distribution of WT (solid red) and pTyr371-N-Cbl (dashed orange). c Normalized Kratky plot of WT and pTyr371-N-Cbl coloured as in (a). d EOM 2.0 distributions of the random pool (black) and the ensembles of WT and pTyr371-N-Cbl coloured as in (b)

Table 2 SAXS parameters for wild-type N-Cbl and pTyr371-N-Cbl

\begin{tabular}{lll}
\hline Parameter & Wild-type & pTyr371 \\
\hline$R_{\mathrm{g}}[P(r)]$ & $2.4 \mathrm{~nm}$ & $2.8 \mathrm{~nm}$ \\
$R_{\mathrm{g}}[$ Guinier $]$ & $2.4 \mathrm{~nm}$ & $2.8 \mathrm{~nm}$ \\
$D_{\max }$ & $7.0 \mathrm{~nm}$ & $9.2 \mathrm{~nm}$ \\
$V_{\text {Porod }}$ & $66.5 \mathrm{~nm}^{3}$ & $71.5 \mathrm{~nm}^{3}$ \\
$V_{\text {Dammif }}$ & $86.5 \mathrm{~nm}^{3}$ & $95.5 \mathrm{~nm}^{3}$ \\
$M_{\text {Porod }}$ & $43 \mathrm{kDa}$ & $46 \mathrm{kDa}$ \\
$M M_{\text {Dammif }}$ & $44 \mathrm{kDa}$ & $47 \mathrm{kDa}$ \\
\hline
\end{tabular}

$R g$ radius of gyration, $D_{\max }$ maximum particle distances, $V$ volume, $M M$ molecular mass indicate significant conformational changes in $\mathrm{N}-\mathrm{Cbl}$ upon phosphorylation of Tyr371. The presence of an extended tail in the $P(r)$ function of pTyr371-N-Cbl (Fig. 2b, Additional file 1: Figure S2) suggests rearrangements of the RING domain that make the particle more elongated as compared to the native one. In addition, the normalized Kratky plots (Fig. 2c) for wild-type and pTyr371-N-Cbl demonstrate significant differences. The wild-type reveals the peak at $\mathrm{s} R_{\mathrm{g}} \approx$ $\sqrt{ } 3$, as expected for globular particles [24], whereas for pTyr371-N-Cbl the peak position is significantly shifted suggesting the presence of structural disorder. 
The theoretical scattering computed from the native, unphosphorylated crystal structure (PDB:2Y1M) gives an overall reasonable fit to the experimental data but also displays some systematic deviations (Fig. 2a). These deviations point to possible differences between solution and crystalline states of the native protein. The crystal structure was therefore refined using an iterative normal mode analysis [25]. This procedure yielded a

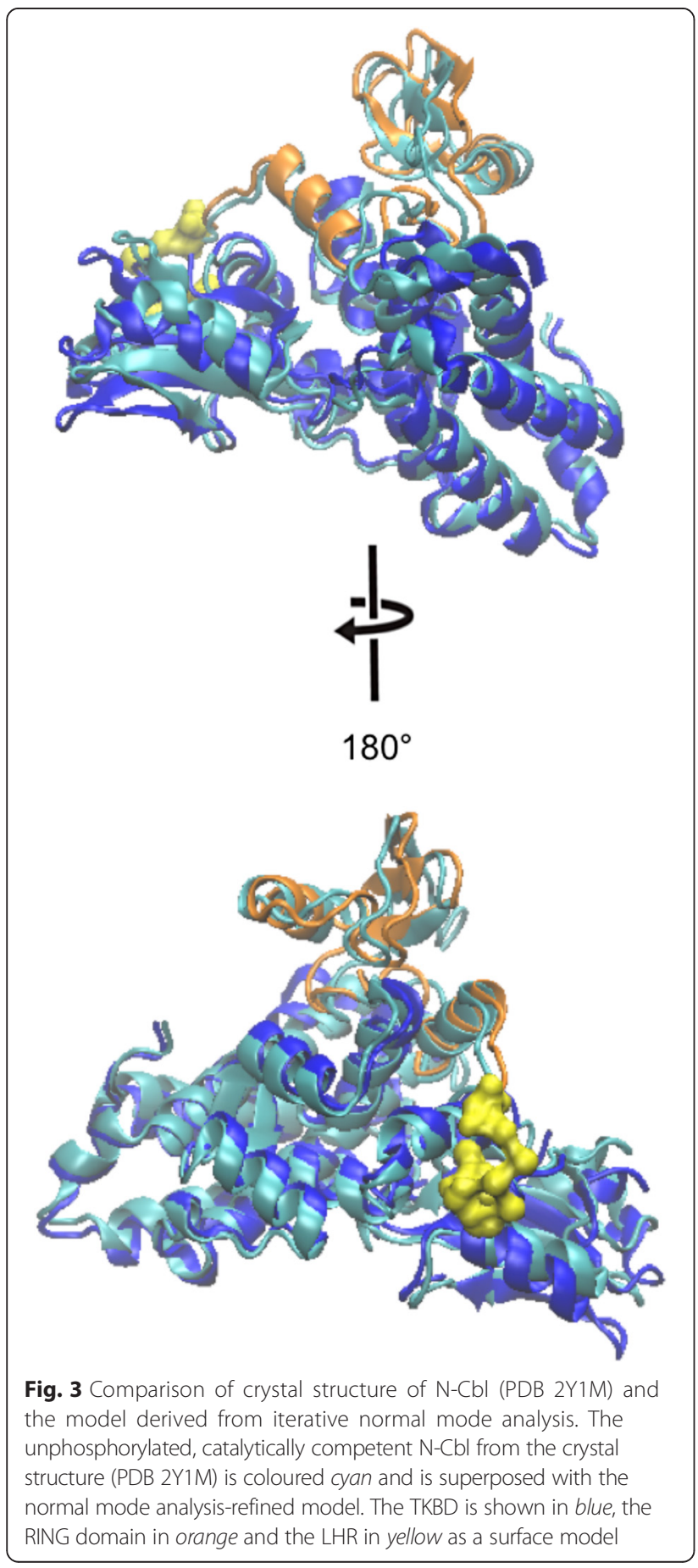

model which was similar to the original structure (root mean square deviation $1.015 \AA$ ) and provided a significant improvement of the fit from $X=2.05$ to 0.95 . Ab initio shape reconstruction further confirms the globular state of unphosphorylated $\mathrm{Cbl}$ (Fig. 3, Additional file 1: Figure S3).

Given the expected flexibility of pTyr371-N-Cbl, structural modelling was performed using an Ensemble Optimization Method (EOM) [45]. Here, ensembles of models with variable conformations are selected from a pool of randomly generated models such that the scattering from the ensemble fits the experimental data, and the distributions of the overall parameters (e.g. $R_{\mathrm{g}}$ ) in the selected pool are compared to the original pool. As a negative control, EOM was first used on the data from $\mathrm{N}-\mathrm{Cbl}$ and the selected ensembles showed predominantly compact conformations (Fig. 2d). In contrast, the selected ensembles for $\mathrm{pTyr} 371-\mathrm{N}-\mathrm{Cbl}$ displayed broader distributions of predominantly extended conformations, which were on average more extended than the random pool (Fig. 2d). These data indicate that pTyr371-N-Cbl is extended and flexible in solution, suggesting that phosphorylation of the LH allows the RING domain to adopt multiple conformations in solution and access multiple surfaces of the TKBD (Fig. 4).

\section{Characterization of $\mathrm{N}-\mathrm{Cb}$ mutants by SAXS}

To study how LHR-TKBD interactions influence the flexibility of LL1 in solution, we performed SAXS on a concentration series of our N-Cbl Tyr371 mutants, N-Cbl Y368F and N-Cbl M222E. The monomeric state of all $\mathrm{N}-\mathrm{Cbl}$ variants was confirmed by the SAXS-derived overall parameters (Additional file 1: Table S2) and gel filtration chromatography (data not shown) with the exception of $\mathrm{N}-\mathrm{Cbl} \mathrm{Y} 371 \mathrm{C}$, where strong concentrationdependent effects were observed; for this reason, $\mathrm{N}-\mathrm{Cbl}$ Y371C was omitted from further SAXS analysis. For the remaining $\mathrm{N}-\mathrm{Cbl}$ variants, the deduced MMs ranged from 41 to $48 \mathrm{kDa}$ pointing to a monomeric state in solution.

Comparison of the SAXS-derived parameters as well as quantification of the flexibility $\left(R_{\text {flex }}\right)$ estimated by using EOM revealed a link between the conformation of $\mathrm{N}-\mathrm{Cbl}$ in solution and the extent of perturbation of the Tyr371-TKBD interaction similar to the trend observed in our SPR data (Tables 1 and 3 and Fig. 5). Our N-Cbl Y371 variants were classified into four categories, depending on the extent of LHR-TKBD perturbation observed based on our SPR findings: complete (pTyr371-N-Cbl), strongly-perturbing (Y371S, Y371D, Y371E), moderately perturbing (Y371A, Y371H, Y371C), and non-perturbing (Y371F). pTyr371-N-Cbl, which abolishes the LHRTKBD interaction, appears the most elongated, whereas unphosphorylated, wild-type $\mathrm{N}-\mathrm{Cbl}$ appears more compact. Compared to wild-type $\mathrm{N}-\mathrm{Cbl}$, the strongly 


\begin{tabular}{rccc}
\hline & $\begin{array}{c}\boldsymbol{R}_{\mathrm{g}} \\
(\sim \mathrm{nm})\end{array}$ & $\begin{array}{c}\boldsymbol{D}_{\max } \\
(\sim \mathrm{nm})\end{array}$ & $\begin{array}{c}\text { Fraction } \\
(\%)\end{array}$ \\
\hline Ochre & 2.72 & 9.20 & $\sim 22.2$ \\
Red & 2.72 & 9.49 & $\sim 33.3$ \\
Gray & 3.12 & 11.17 & $\sim 11.1$ \\
Yellow & 2.88 & 9.59 & $\sim 5.5$ \\
Tan & 2.92 & 9.67 & $\sim 5.5$ \\
Silver & 2.81 & 9.52 & $\sim 5.5$ \\
Green & 2.89 & 9.75 & $\sim 5.5$ \\
Pink & 3.04 & 10.52 & $\sim 5.5$ \\
Purple & 3.04 & 10.89 & $\sim 5.5$ \\
Average & $\underline{2.84}$ & $\underline{9.76}$ & \\
\hline
\end{tabular}
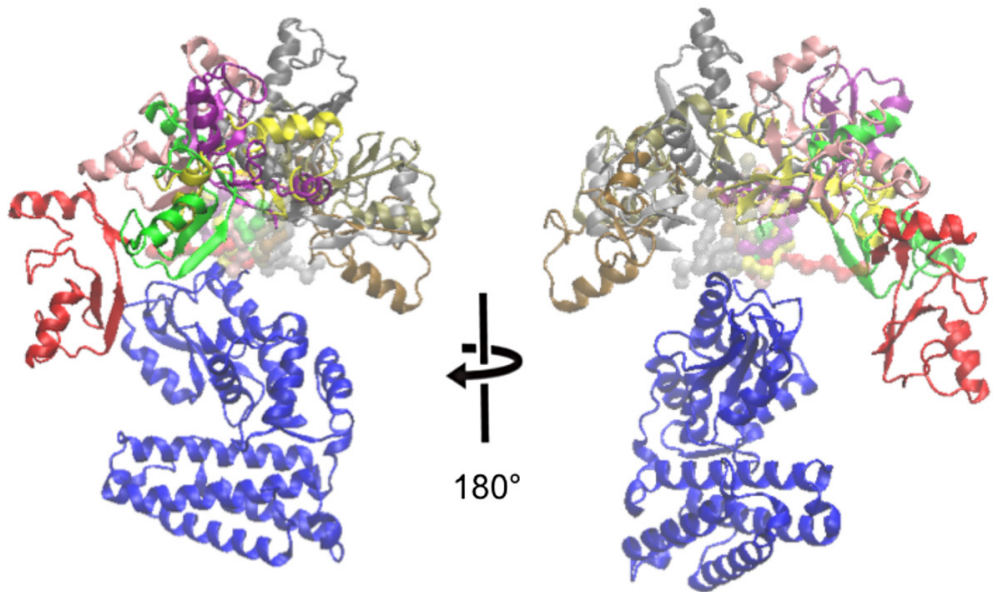

Fig. 4 Cartoon ensemble representation of pTyr371-N-Cbl. The TKBD domain is coloured blue. The predicted RING domain conformations are shown in several colours as indicated in the table. The missing loops connecting the RING and TKBD domains are coloured according to the corresponding RING domains but presented as transparent surfaces

Table 3 Average ensemble outcome $R_{\mathrm{g}}$ and $D_{\max }$ from EOM 2.0 together with the $X$ value and the quantification of flexibility $\left(R_{\text {flex }}\right)$ for each $\mathrm{N}$-Cbl variant

\begin{tabular}{lcccl}
\hline N-Cbl variant & $R_{\mathrm{g}}(\mathrm{nm})$ & $D_{\max }(\mathrm{nm})$ & Fit $(X$ value $)$ & $R_{\text {flex }}(\%)$ \\
\hline Y371F & 2.38 & 7.67 & 1.284 & 56 \\
WT & 2.41 & 7.89 & 0.831 & 60 \\
Y368F & 2.46 & 8.37 & 0.778 & 65 \\
M222E & 2.44 & 8.05 & 1.030 & 65 \\
Y371H & 2.44 & 8.24 & 0.695 & 69 \\
Y371A & 2.52 & 8.16 & 1.020 & 75 \\
Y371S & 2.61 & 8.89 & 0.774 & 84 \\
Y371D & 2.64 & 8.91 & 0.814 & 88 \\
Y371E & 2.79 & 9.43 & 0.773 & 90 \\
\hline
\end{tabular}

perturbing mutants, N-Cbl Y371S, Y371E and Y371D, are partially elongated $\left(R_{\mathrm{g}} \mathrm{s}\right.$ are $2.6,2.7$ and $2.7 \mathrm{~nm}$, respectively) but not as much as pTyr371-N-Cbl. Conformational rearrangements of these mutants are also confirmed by the corresponding $R_{\text {flex }}$ values of approximately $84 \%, 90 \%$ and $88 \%$ compared to approximately $60 \%$ for wild-type N-Cbl. The moderately and nonperturbing mutants have $R_{\mathrm{g}}$ and $D_{\max }$ values more similar to the wild-type $\mathrm{N}-\mathrm{Cbl}$, although with different degrees of flexibility (Table 3 and Fig. 5). Notably, N-Cbl Y371F appears slightly more compact and less flexible than wildtype N-Cbl, with an $R_{\mathrm{g}}$ of $2.38 \mathrm{~nm}$, a $D_{\max }$ of $7.67 \mathrm{~nm}$, and an $R_{\text {flex }}$ of approximately $56 \%$. Together with SPR, these data demonstrate that, in solution, RING domain accessibility is connected to $\mathrm{N}-\mathrm{Cbl}$ conformational rearrangements induced by mutation or modification of Tyr371 in the LHR.

The Tyr371-TKBD interaction appears to play a critical role in mediating how elongated $\mathrm{N}-\mathrm{Cbl}$ is in solution. 

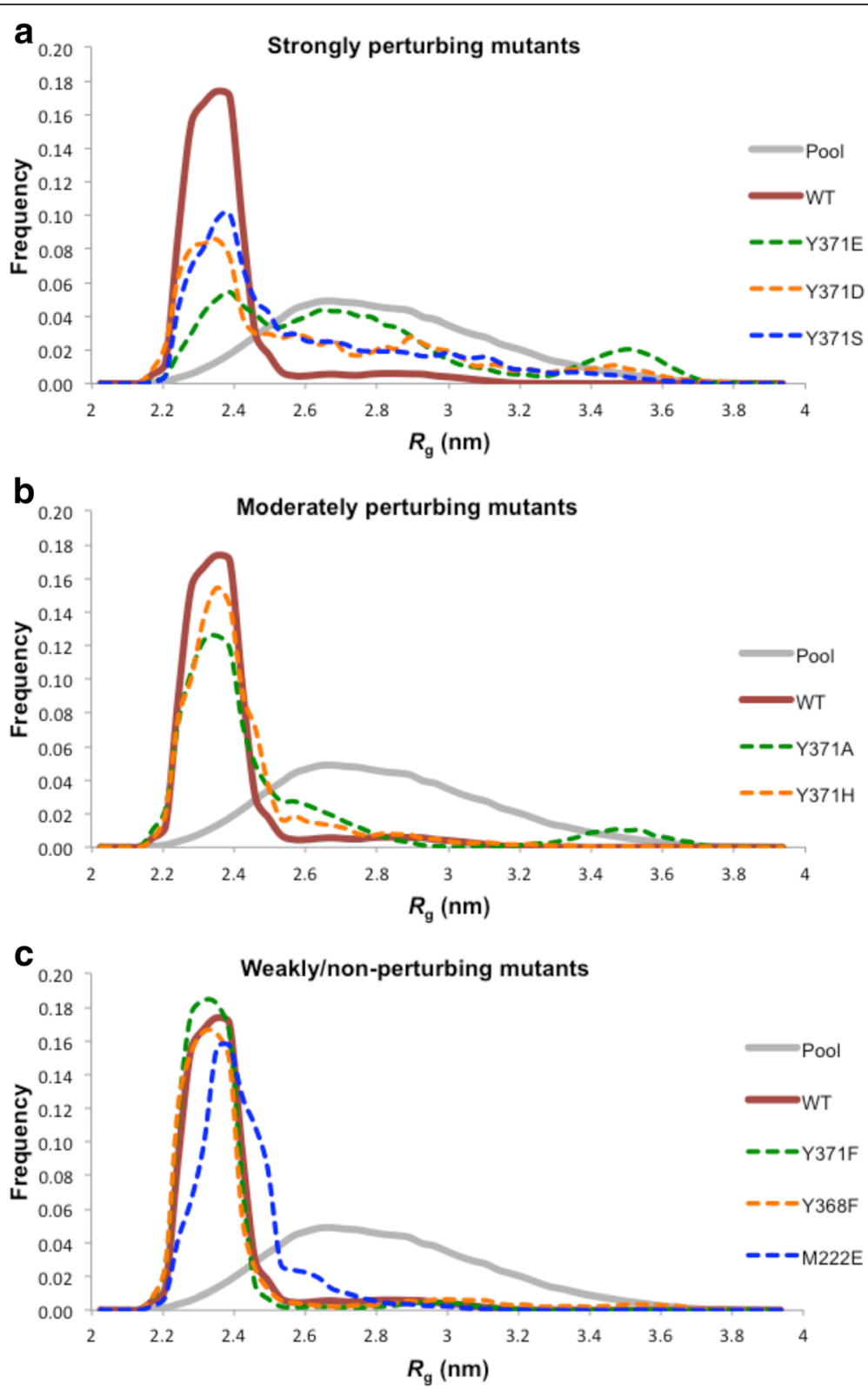

Fig. 5 EOM 2.0 analysis of N-Cbl Tyr371 mutants, N-Cbl Y368F and N-Cbl M222E. Mutants were clustered according to their ability to perturb the LHR-TKBD interaction based on SAXS parameters shown in Table 3. a Strongly perturbing mutants. b Moderately perturbing mutants. c Weakly or non-perturbing mutants

Although N-Cbl Y368F and M222E have higher binding affinities for UbcH5B-Ub than wild-type, at SAXS resolution both have characteristics comparable to wild-type, suggesting they are similarly compact in solution. Although N-Cbl M222E has a comparable binding affinity to the strongly-perturbing $\mathrm{N}-\mathrm{Cbl} \mathrm{Y} 371$ mutants, in solution, it appears more compact, as both $R_{\mathrm{g}}$ and $D_{\max }$ are similar to wild-type $\mathrm{N}-\mathrm{Cbl}$ and flexibility is relatively limited $\left(R_{\text {flex }} \sim 60 \%\right)$. N-Cbl Y368F has a higher binding affinity for UbcH5B-Ub than wild-type, but at the level of resolution provided by SAXS its characteristics and compactness are similar to those of the wild-type protein, suggesting similar behaviour in solution.

\section{Transformation potential of Cbl Y371 mutants in cells}

To test the transforming potential of Cbl Y371 mutants in cells, we performed focus formation assays using 3T3 cells stably transfected with N-terminally FLAG-tagged Cbl variants. Relative protein expression levels of each variant were assessed by immunoblotting (Fig. 6a). Foci 

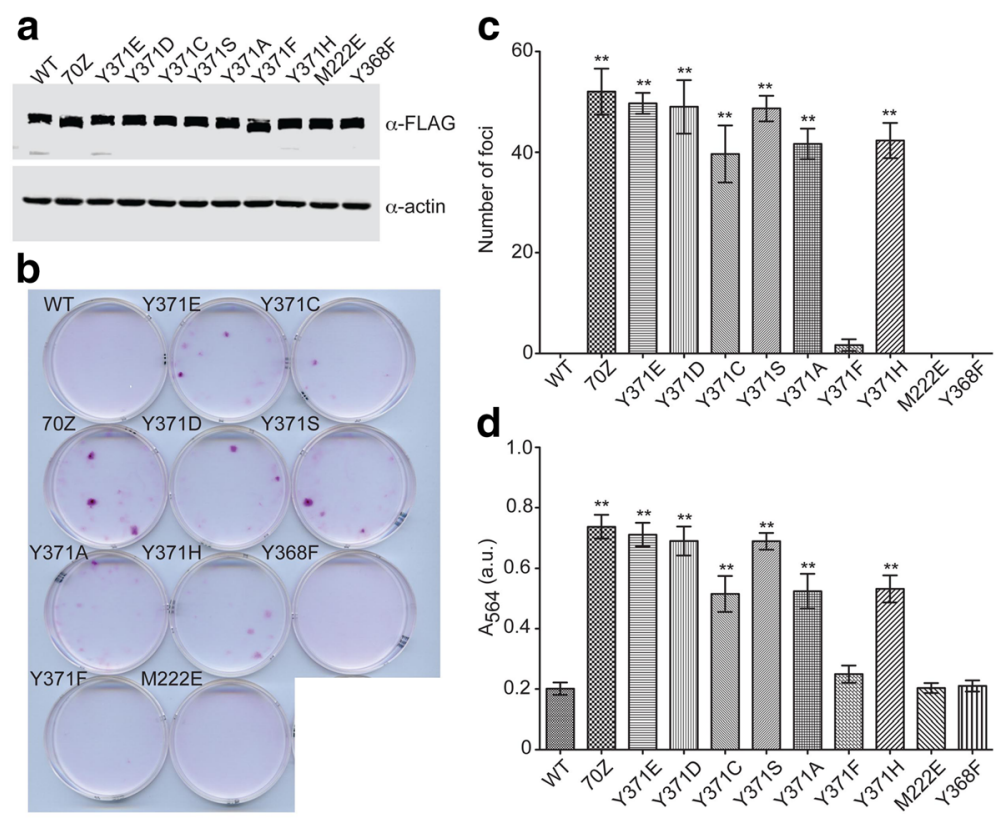

Fig. 6 Transformation potential of Cbl variants in focus formation assays. a Immunoblot of lysates from 3T3 fibroblasts infected with FLAG-tagged $\mathrm{Cbl}$ variants using a-FLAG antibody (top) and a-actin (bottom) antibody as a loading control. b Sulforhodamine B-stained 3T3 fibroblasts infected with indicated $\mathrm{Cbl}$ variants. c Mean number of foci formed by Cbl variant-infected 3T3 fibroblasts shown in a bar graph $(n=3)$. No foci were present in 3 T3 cells infected with wild-type Cbl, Cbl M222E or Cbl Y368F. Double asterisks $\left(^{* *}\right)$ denote significant differences $(P<0.05)$ between indicated $\mathrm{Cb}$ variant and wild-type using ANOVA followed by Dunnett's multiple comparisons test. Error bars indicate standard deviation. $\mathbf{d}$ As in (c) but for $\mathrm{A}_{564}$ of extracted sulforhodamine $\mathrm{B}$ from Cbl-infected 3 T3 fibroblasts

were visualized with sulforhodamine B staining and counted manually with a DNA Safe Imager (Invitrogen). Afterwards, the sulforhodamine $B$ stain was extracted and the $\mathrm{A}_{564}$ measured to compare relative cell densities $[26,27]$. Foci counts and relative cell densities were analyzed by one-way ANOVA followed by Dunnett's test with wild-type $\mathrm{Cbl}$ as the control. Cbl70Z was included among the variants tested as a positive transforming control [22]. Other variants tested included the same set used in our biochemical assays except in a full-length context.

Foci were observed in cells transfected with Cbl Y371 mutants and Cbl70Z, but not in wild-type, Cbl Y368For Cbl M222E-transfected cells (Fig. 6). When analyzed by one-way ANOVA followed by Dunnett's test, significant differences $(P<0.05)$ in number of foci and cell densities were observed between cells infected with wildtype $\mathrm{Cbl}$ and all the Y371 mutants except Cbl Y371F (Fig. 6c,d, Additional file 1: Figure S4). Significantly more foci were present in Cbl70Z, Cbl Y371E and the MDS/ MPN Cbl Y371 mutant set and the relative cell density was significantly greater compared to wild-type Cbl; however, there is no correlation between mutations that promote moderate or strong LHR-TKBD perturbations and transformation potential. Based on the ability to form foci, all the $\mathrm{Cbl}$ variants except $\mathrm{Cbl} \mathrm{Y368F}$ and M222E have the ability to potentiate transformation in cells. Based on statistical analyses of the number of foci and relative cell density, Cbl70Z, Cbl Y371E and the MDS/MPN Cbl Y371 mutant set have significantly higher numbers of foci than wild-type Cbl. For Cbl Y371F, neither the number of foci nor the relative cell density are significantly different than in cells infected with wild-type $\mathrm{Cbl}$; these results suggest this mutant may potentiate transformation but not to the same extent as the other Cbl Y371 mutants or Cbl70Z.

\section{Discussion}

In this work, we employed SAXS and SPR to characterize how modifications and mutations in $\mathrm{Cbl}$ affect the conformation and accessibility of the RING domain in solution and subsequently investigate the relationship between these characteristics and the ability of $\mathrm{Cbl}$ variants to potentiate transformation in cells. Our results show that a mutation (M222E) within the RING-TKBD interface regulates accessibility of the RING domain only, whereas mutation or modification of Tyr371 within the LHR mediates the LHR-TKBD interaction, thereby regulating RING domain accessibility as well as the space sampled by the RING domain relative to the TKBD. The chemical nature of the substitution or modification controls the LHRTKBD interaction and shifts the equilibrium between the native conformation where the RING is restricted to the 
face of the TKBD opposing the substrate-binding site and open conformations where the RING domain can access other surfaces of the TKBD and potentially other regions of Cbl. None of the Tyr371 mutants can adopt the pTyr371 conformation that is critical for activation of E2 Ub and RTK ubiquitination, but all of the Tyr371 mutants perturb the LHR-TKBD conformation observed in the native state except Cbl Y371F. Likewise, all of the Tyr371 mutants except Cbl Y371F clearly potentiate transformation in our focus formation assays, whereas $\mathrm{Cbl}$ Y371F forms foci but statistical analyses of the number of foci formed and relative cell densities suggest that this mutant has less transformation potential than the others. Previous studies have shown that Cbl Y371F is not transforming in soft agar colony formation assays nor does it promote tumour formation in nude mice [21, 22]. These data indicate that the flexibility of the LHR features in the Cbl Tyr371 mutant transformation mechanism.

Met222 is a key residue in maintaining the RINGTKBD interaction in native Cbl. A Met to Glu mutation was used to perturb this interaction and investigate the importance of the RING-TKBD interaction on Cbl's conformation in solution. Our previous work and SPR studies show that mutation of Met222 in the TKBD to Glu increases Cbl's E2-Ub binding affinity by approximately 8-fold and enhances Cbl's in vitro autoubiquitination rate [6]. Though Cbl M222E has a higher binding affinity for UbcH5B-Ub and is more active than wildtype Cbl, SAXS analysis demonstrates that Cbl M222E has parameters $\left(R_{\mathrm{g}}, D_{\max }\right.$ and $\left.R_{\mathrm{flex}}\right)$ comparable to wildtype $\mathrm{Cbl}$, suggesting both adopt a compact conformation. In cells, Cbl M222E does not enhance EGFR ubiquitination (data not shown) nor does it potentiate transformation in our focus formation assays. The lack of effect of this mutant in these assays suggests structural regulation of Cbl's ligase activity requires more than a simple rotation that exposes the E2-binding site on the RING domain.

Previous work has shown that phosphorylation of the conserved LHR Tyr in the Cbl family enhances activity in vitro and is essential for receptor PTK ubiquitination in cells, where Cbl's E3 ligase activity features prominently in EGFR downregulation via lysosomal degradation $[8,10,11]$. The rate and pattern of Cbl-mediated EGFR ubiquitination determines whether EGFR is directed to the lysosome or recycled to the membrane. X-ray crystallography and NMR studies of $\mathrm{Cbl}$ and $\mathrm{Cbl}-\mathrm{b}$ have shown that this phosphorylation event eliminates RINGmediated autoinhibition, optimally positions Ub for transfer and juxtaposes the RING domain with the TKBD substrate-binding site $[6,7,9]$. Notably, in the crystal structures of $\mathrm{Cbl}$ and $\mathrm{Cbl}-\mathrm{b}$ bound to Zap70 peptide and E2 or E2 Ub, the conformations of RING domain relative to the TKBD are identical. Here, we show that, in solution, when Tyr371 is phosphorylated, the $R_{\mathrm{g}}$ and $D_{\max }$ increase and EOM analysis demonstrates the linker region becomes flexible, allowing the RING domain to sample the space surrounding the TKBD rather than maintain the crystallographically observed conformation. This is consistent with other E3 ligases, where translational and rotational movement of the RING domain are required for Ub transfer to select substrate lysine sites (monoubiquitination and multiubiquitination) as well as polyUb chain formation [28]. Cbl binds EGFR directly through its TKBD and indirectly through growth factor receptor binding 2-mediated interactions in the region $\mathrm{C}$-terminal to the RING domain [12]. Cbl-mediated ubiquitination of EGFR is observed for both binding sites, highlighting a potential essential role for RING flexibility in Cbl substrate ubiquitination.

Our SAXS and SPR data show that mutations within the LHR perturb the native LHR-TKBD conformation and that the extent of perturbation is dependent on the chemical nature of the amino acid substitution. In the native state, Trp258, Ala262, Val263, and Met274 form a hydrophobic pocket around the aromatic ring of Tyr371 and the side chain of Ser227 forms a hydrogen bond with the hydroxyl group of Tyr371. The more disruptive the mutation is to the hydrophobic environment, the greater the perturbation in the LHR-TKBD interaction. When Tyr371 is mutated to an amino acid with a charged side chain like Asp or Glu or a small, polar side chain like Ser, the UbcH5B-Ub binding affinity is approximately 8-fold enhanced compared to native $\mathrm{Cbl}$ and the $R_{\mathrm{g}}$ and $D_{\max }$ increase to values comparable to pTyr371Cbl. Additionally, SAXS analysis reveals these Tyr371 mutants are the most flexible compared to native $\mathrm{Cbl}$. Mutation of Tyr371 to smaller hydrophobic amino acids like Cys or Ala only moderately perturbs the LHR-TKBD interaction as evidenced by an approximately 2-fold enhancement in the UbcH5B-Ub binding affinity and the moderate increase in $R_{\mathrm{g}}, D_{\max }$ and $R_{\mathrm{flex}}$ compared to native Cbl. Likewise, when Tyr371 is mutated to His, only moderate to weak perturbation of the LHR-TKBD interaction occurs. There is an approximately 2 -fold enhancement in the UbcH5B-Ub binding affinity and SAXS analysis shows evidence of more flexibility (slightly higher values of $R_{\mathrm{g}}, D_{\max }$ and $R_{\mathrm{flex}}$ ) compared to native $\mathrm{Cbl}$. When Tyr371 is mutated to Phe, the hydrophobic interactions are not disturbed and the native state is maintained: the UbcH5B-Ub binding affinity, $R_{\mathrm{g}}, D_{\max }$ and $R_{\mathrm{flex}}$ values are comparable to native $\mathrm{Cbl}$. In addition, previous in vitro autoubiquitination assays show native $\mathrm{Cbl}$ and $\mathrm{Cbl}$ Y371F have comparable catalytic efficiencies [6]. Thus, in solution, it appears as though Cbl Y371F mimics the behaviour of native $\mathrm{Cbl}$.

Mutation of Tyr371 is not the only site at which the LHR-TKBD interaction can be perturbed. Our previous work and current data show that mutation of Tyr368 to 
Phe also disrupts the LHR-TKDB interaction [6]. Cbl Y368F binds UbcH5B-Ub approximately 2-fold more tightly than native $\mathrm{Cbl}$ and has an approximately 2 -fold enhancement in catalytic efficiency for in vitro autoubiquitination. In addition, this mutant displays a slight increase in all SAXS-based parameters (including $R_{\text {flex }}$ ) compared to native $\mathrm{Cbl}$. However, in contrast to the $\mathrm{Cbl}$ Tyr371 mutants, Cbl Y368F does not promote focus formation in our assays nor does it compromise EGFR ubiquitination in cells [6] and previous work has also shown this mutant does not form colonies in soft agar assays nor promote tumour growth in nude mice [21, 22]. Though it is clear that Tyr368-TKBD interactions also play a role in the conformations $\mathrm{Cbl}$ adopts in solution, the significance of this interaction in Cbl's ligase activity in cells is unclear. Other studies have shown that Cbl $\Delta Y 368$ is defective in EGFR ubiquitination and has the ability to potentiate transformation in cells and in mice [21, 22]. In addition, Cbl Y368C has also been identified in MDS/ MPN clinical samples, and, like Cbl Y371C and Y371S, has been shown to potentiate transformation in cells and in mice; however, whether PTK ubiquitination is compromised remains unknown [19]. As observed for Tyr371, the chemical nature of the mutation at Tyr368 might factor into regulation of Cbl's ligase activity as well as transformation potential.

While the ability to ubiquitinate PTKs is essential for Cbl-mediated downregulation of PTK signalling, previous work has clearly shown that it is not the only prerequisite for Cbl-dysfunction driven transformation. Thien et al. [21] propose that the LHR-TKBD stability of Cbl mutants contributes to their ability to potentiate transformation based on the analysis of a number of linker region and RING mutants: Cbl $\Delta \mathrm{Y} 368, \Delta \mathrm{Y} 371$ and $\mathrm{Y} 371 \mathrm{~A}$ promote transformation but not Cbl Y368F or Y371F. Cbl Y368F is slightly more flexible than native $\mathrm{Cbl}$ but retains the ability to ubiquitinate receptor PTKs, whereas Cbl Y371F cannot ubiquitinate receptor PTKs but is able to maintain the native conformation in solution. Thus, it seems that both characteristics contribute to the transformation potential of $\mathrm{Cbl}$ mutants. Cbl functions as both an ubiquitin ligase and adaptor in receptor PTK-mediated cell signalling. Although enzymatic activity is slower in the absence of Tyr371 phosphorylation, $\mathrm{Cbl}$ is still functional [6]. It may be that when the LHR-TKBD interaction is perturbed, $\mathrm{Cbl}$ ubiquitinates substrates that bind to regions other than the canonical TKBD-binding site or the more flexible mutants might ubiquitinate "dead end" lysines on substrates such that biologically viable ubiquitination chains are not formed. Alternatively, perturbed LHR-TKBD interactions might disrupt oligomerization or interactions with other proteins or lead to the non-sequential recruitment of substrates to exposed surfaces that interfere with controlled signalling.

\section{Conclusions}

We have shown that LHR-TKBD interactions regulate Cbl's ligase activity and conformations in solution. $\mathrm{Mu}-$ tations or modifications within the LHR prevent $\mathrm{Cbl}$ from maintaining a closed conformation where the RING domain is restricted to a surface opposite the TKBD-substrate binding site; instead, depending on the nature of the alteration, $\mathrm{Cbl}$ becomes flexible and the RING domain can access multiple surfaces of the TKBD. Transformation only occurs when mutations within the LHR (1) perturb the native state and (2) fail to ubiquitinate PTKs.

\section{Methods}

\section{Protein preparation}

For crystallization, N-Cbl Y371F (residue 47-435) was expressed, purified and stored as described previously [6]. For SPR and SAXS analysis, N-Cbl variants were cloned into a modified form of pGEX4T1 (GE Healthcare) containing an $\mathrm{N}$-terminal histidine glutathione $\mathrm{S}$ transferase (His-GST) tag followed by a thrombin or TEV-protease cleavage site and expressed in E. coli BL21 (DE3) Gold. pTyr371-N-Cbl was generated as described previously [6]. For SPR analysis, all N-Cbl variants were purified by Ni-NTA followed by glutathione-affinity chromatography. Anion exchange chromatography was subsequently used to separate His-GST-pTyr371-N-Cbl from unphosphorylated His-GST-N-Cbl. For SAXS studies, N$\mathrm{Cbl}$ variants were then treated with TEV or thrombin protease to cleave the His-GST tag and further purified by Ni-NTA pass-back followed by anion exchange and size exclusion chromatography. Proteins for SAXS were stored in $25 \mathrm{mM}$ Tris- $\mathrm{HCl}$ (pH 7.6), $500 \mathrm{mM} \mathrm{NaCl}$ and $1 \mathrm{mM}$ DTT at $-80{ }^{\circ} \mathrm{C}$. UbcH5B S22R C85K-Ub (referred to as $\mathrm{UbcH} 5 \mathrm{~B}-\mathrm{Ub}$ ) was expressed, generated and purified as described previously [7]. His-GST-tagged protein concentrations were determined by Bradford assay using BSA as a standard and all other concentrations were determined using a NanoVue Spectrophotometer (GE Healthcare).

\section{Crystallization and structural determination}

Crystals were obtained by mixing N-Cbl Y371F $(10 \mathrm{mg} / \mathrm{mL})$ with an equal volume of reservoir solution containing 0.1 M Tris- $\mathrm{HCl}, \mathrm{pH}$ 8.5, 3.0-3.1 M sodium formate, and $5 \mathrm{mM}$ DTT using hanging drop vapour diffusion at $8{ }^{\circ} \mathrm{C}$. The crystals were flash-frozen in $0.1 \mathrm{M}$ Tris- $\mathrm{HCl}$, $\mathrm{pH}$ 8.5, 3.0-3.1 M sodium formate, $5 \mathrm{mM}$ DTT, $8 \%$ (v/v) glycerol, $8 \%(\mathrm{v} / \mathrm{v})$ ethylene glycol, and $8 \%(\mathrm{v} / \mathrm{v})$ sucrose. Data were collected with beamline I04 at Diamond Light Source, integrated with automated XDS [29] and scaled using the CCP4 program suite [30]. Initial phases were obtained by molecular replacement with PHASER using native N-Cbl (PDB:2Y1M) [6]. N-Cbl Y371F crystals belong to space group $\mathrm{C} 222_{1}$ with six 
molecules in the asymmetric unit. The model was built in COOT [31] and refined using PHENIX [32].

\section{Biacore analysis}

$\mathrm{Cbl}-\mathrm{UbcH} 5 \mathrm{~B}-\mathrm{Ub}$ binding experiments were conducted as described previously [6, 23]. GST-Cbl variants were coupled to CM- 5 chips and binding was measured at a concentration range of $0-120 \mu \mathrm{M}$ of UbcH5B-Ub. The data were analyzed using Biacore T200 Evaluation software package (Biacore Life Sciences) and Scubber2.0c (BioLogic Software).

\section{Plasmids and cell culture}

$\mathrm{N}$-terminally FLAG-tagged Cbl variants were generated by PCR amplification and ligation into a pBABE vector [33] by In-Fusion (Clontech) according to the manufacturer's instructions. Subsequently, these $\mathrm{Cbl}$ variants were transiently transfected into Phoenix Eco cells using Lipofectamine 2000 (Thermo Fisher Scientific) according to the manufacturer's instructions. Infection was performed in 3T3 (mouse fibroblast) cells followed by puromycin $(2 \mu \mathrm{g} / \mathrm{mL})$ selection. Cells were cultured in DMEM containing $20 \mathrm{mM}$ glutamine and $10 \%$ donor bovine serum in a $37^{\circ} \mathrm{C}$ incubator at $5 \% \mathrm{CO}_{2}$.

\section{Focus formation assays and sulforhodamine B extraction}

To perform the focus formation assays, $3 \mathrm{~T} 3$ cells were seeded onto $10 \mathrm{~cm}^{2}$ dishes and infected with the $\mathrm{Cbl}$ variants on the following day. This was followed by a second round of infection after 24 hours and the media changed on the following day. After 3 days of selection with puromycin, the $3 \mathrm{~T} 3$ cells were split and $0.5 \times 10^{5}$ cells seeded onto $3.5 \mathrm{~cm}^{2}$ dishes and cultured for 18 days before being fixed in methanol and stained with sulforhodamine B. Foci were then counted manually with a DNA Safe Imager (Invitrogen). Afterwards, each dish was incubated with $1.1 \mathrm{~mL}$ of $10 \mathrm{mM}$ Tris, $\mathrm{pH} 10.5$ for 5 minutes with rocking at room temperature to extract sulforhodamine $\mathrm{B}$ and the absorbance of the extracted dye was measured at $564 \mathrm{~nm}$. Prism (Graph Pad, Mac V5.0C) was used for statistical analyses (one-way ANOVA followed by Dunnett multiple comparisons testing with $P<0.05$ treated as the cutoff for significant differences).

\section{Immunoblotting}

After 1 week, total protein was isolated from one $3.5 \mathrm{~cm}^{2}$ dish of each Cbl variant in whole cell lysis buffer containing $50 \mathrm{mM}$ Tris, pH 7.4, $150 \mathrm{mM} \mathrm{NaCl}, 1 \mathrm{mM}$ EDTA, $1 \%$ Igepal CA-630 (Sigma), and $10 \%$ glycerol. Proteins were separated under reducing conditions using SDS polyacrylamide gel electrophoresis and transferred onto a nitrocellulose membrane (GE Healthcare Life Sciences). Blots were probed with rabbit anti-FLAG (Sigma Aldrich,
F7425) and goat anti-actin (SantaCruz Biotechnology, sc-1616) antibodies, incubated with donkey anti-goat IRDye $800 \mathrm{CW}$ and goat anti-rabbit IRDye $680 \mathrm{LT}$ secondary antibodies (LI-COR Biosciences, 925_32214 and 925_68021), and visualized using an Odyssey CLx Imaging System (LI-COR Biosciences).

\section{Small angle X-ray scattering}

Synchrotron X-ray scattering data of $\mathrm{Cbl}$ mutants were collected at EMBL P12 beamline (DESY, Hamburg) using a robotic sample changer [34]. All the mutants were measured in the same buffer $(500 \mathrm{mM} \mathrm{NaCl}, 25 \mathrm{mM}$ Tris- $\mathrm{HCl}$ ( $\mathrm{pH}$ 7.6), $1 \mathrm{mM}$ DTT) in a concentration series ranging from either $0.5-10 \mathrm{mg} / \mathrm{mL}(0.5,1,2,5$, and $10 \mathrm{mg} / \mathrm{mL})$ or $0.5-6.6 \mathrm{mg} / \mathrm{mL}(0.5,1,1.6,3.3$, and $6.6 \mathrm{mg} / \mathrm{mL})$. SAXS data were recorded at $10^{\circ} \mathrm{C}$ using a PILATUS $2 \mathrm{M}$ pixel detector (DECTRIS, Baden, Switzerland) at a sampledetector distance of $3.1 \mathrm{~m}$ and a wavelength of $0.15 \mathrm{~nm}$. This setup covers a range of momentum transfer of $0.1<s<5 \mathrm{~nm}^{-1}(s=4 \pi \sin (\theta) / \lambda$, where $2 \theta$ is the scattering angle). Initially, the data were pre-processed using an automatic pipeline [35] and further analyzed using PRIMUS [36, 37]. The forward scattering $I(0)$ as well as the $R_{\mathrm{g}}$ were calculated using the Guinier approximation assuming that, at very small angles $\left(s<1.3 / R_{\mathrm{g}}\right)$, the intensity is represented as $I(s)=I(0) \cdot \exp \left(-\left(s R_{\mathrm{g}}\right)^{2} / 3\right)$ [38]. Linearity in the Guinier region was used to exclude sample aggregation. The pair-distance distribution function $P(r)$, from which the $D_{\max }$ and $R_{\mathrm{g}}$ were estimated, was computed using GNOM [39]. Qualitative assessment of compactness versus structural disorder was made by transforming the scattering profiles in the so-called Kratky representation $\left[I(s) s^{2}\right.$ vs. $\left.s\right][40]$ and its normalized version $\left[\left(s R_{\mathrm{g}}\right)^{2 *} I(s) / I(0)\right.$ vs. $s R_{\mathrm{g}}$ ] [41]. The MM was derived from (1) the excluded volume of the hydrated particle using the Porod invariant [36] and (2) the excluded volumes of the ab initio models. $\mathrm{Ab}$ initio models were created with DAMMIF [42] using low resolution data $\left(s<2 \mathrm{~nm}^{-1}\right)$. The algorithm constructs bead models yielding a scattering profile with the lowest possible discrepancy $(\mathrm{X})$ to the experimental data while keeping beads interconnected and the model compact. Twenty independent ab initio reconstructions were performed for each $\mathrm{Cbl}$ mutant and then averaged using DAMAVER [43]. Superimpositions between ab initio reconstructions and available atomic models were made using the software SUPCOMB [44]. The flexibility was analyzed using EOM 2.0 [45] - an enhanced version of the EOM [46], which assumes coexistence of a range of conformations in solution for which an average scattering intensity fits the experimental data. In EOM 2.0, a pool of 10,000 independent models is created as first step with the aim to approximate the (otherwise infinite) conformational space for a protein exhibiting disorder. For each model in the pool the theoretical scattering curve is 
automatically computed with CRYSOL [47]. Afterwards, genetic algorithm (GA) is used to select ensembles with varying numbers of conformers (usually from 5 to 40) by calculating the average theoretical profile and fitting it to the experimental SAXS data. For each $\mathrm{Cbl}$ mutant, the GA was repeated 100 independent times and the ensemble with the lowest discrepancy reported as the best solution out of 100 final ensembles. Furthermore, 100 repetitions of GA allowed the computation of $R_{\mathrm{g}}$ and $D_{\max }$ distributions so that structural information about the flexibility could be extracted. Distributions with $R_{\mathrm{g}}$ average values above the $R_{\mathrm{g}}$ average values calculated for the pool are classified as extended whereas models with values below the average as compact. The width of the distribution is also used to derive the flexibility of the particle, whereby a narrow distribution indicates a rather rigid particle and broader distributions are associated with higher flexibility [46]. Using EOM 2.0, systematic quantification of the flexibility was made using the metric $R_{\text {flex }}$ - which computes the Shannon information entropy of the distributions [45]. All the software used for the SAXS data analysis belongs to the ATSAS 2.5 package [36].

\section{Additional file}

Additional file 1: Figure S1. Comparison of wild-type and N-Cbl Y371F. Figure S2. Comparison of SAXS scattering data for wild-type (WT, blue) and pTyr371-N-Cbl (yellow). Figure S3. Comparison of ab initio and relaxed crystal models. Figure S4. Confidence intervals (95\%) for the difference between group means. Table S1. Data collection and refinement statistics. (DOCX $15797 \mathrm{~kb})$

\section{Acknowledgements}

We would like to thank W. Clark and A. Keith for in-house DNA sequencing DLS for access to beamline 104 ( $m \times 8659)$, EMBL for the access to P12 beamline, and A. Schuettelkopf, M. Gabrielsen and O. Byron for discussions.

\section{Funding}

This work was supported by Cancer Research UK. DTH was supported by European Research Council (grant number 647849).

\section{Availability of data and materials}

The coordinates and structure factors for N-Cbl Y371F have been deposited in Protein Data Bank (PDB: 5J3X in http://www.rcsb.org).

\section{Authors' contributions}

$L B, D T H$ and HD performed protein purification. HD carried out protein crystallization and X-ray data collection. LB performed structure determination. SFA, AH and LB conducted focus formation assays. LB, DTH and GT performed SAXS experiments. GT and DIS conducted SAXS analyses. GJS performed and analyzed SPR experiments. LB and DTH wrote the manuscript. All authors read and approved the final manuscript.

\section{Competing interests}

The authors declare that they have no competing interests.

\section{Author details}

'Cancer Research UK Beatson Institute, Garscube Estate, Switchback Road, Glasgow G61 1BD, UK. ${ }^{2}$ EMBL c/o DESY, Notkestrasse 85, Geb, 25a, 22603 Hamburg, Germany. ${ }^{3}$ Present address: Institute of Medical Genetics, School of Medicine, Shandong University, No. 44 Wenhuaxi Road, Jinan, Shandong 250012, People's Republic of China. ${ }^{4}$ Present address: Multimodal Molecular
Imaging Institute, Nanoscopy Division, Maastricht University, Universiteitssingel 50, 6229 ER Maastricht, The Netherlands.

Received: 31 March 2016 Accepted: 12 August 2016

Published online: 08 September 2016

\section{References}

1. Mohapatra B, Ahmad G, Nadeau S, Zutshi N, An W, Scheffe S, Dong L, Feng D, Goetz B, Arya P, et al. Protein tyrosine kinase regulation by ubiquitination: critical roles of Cbl-family ubiquitin ligases. Biochim Biophys Acta. 2013;1833(1):122-39.

2. Swaminathan $\mathrm{G}$, Tsygankov AY. The Cbl family proteins: ring leaders in regulation of cell signaling. J Cell Physiol. 2006;209(1):21-43.

3. Ng C, Jackson RA, Buschdorf JP, Sun Q, Guy GR, Sivaraman J. Structural basis for a novel intrapeptidyl $\mathrm{H}$-bond and reverse binding of c-Cbl-TKB domain substrates. EMBO J. 2008;27(5):804-16.

4. Joazeiro CA, Wing SS, Huang H, Leverson JD, Hunter T, Liu YC. The tyrosine kinase negative regulator c-Cbl as a RING-type, E2-dependent ubiquitinprotein ligase. Science. 1999;286(5438):309-12.

5. Zheng N, Wang P, Jeffrey PD, Pavletich NP. Structure of a c-Cbl-UbcH7 complex: RING domain function in ubiquitin-protein ligases. Cell. 2000;102(4):533-9.

6. Dou H, Buetow L, Hock A, Sibbet GJ, Vousden KH, Huang DT. Structural basis for autoinhibition and phosphorylation-dependent activation of c-Cbl. Nat Struct Mol Biol. 2012;19(2):184-92.

7. Dou H, Buetow L, Sibbet GJ, Cameron K, Huang DT. Essentiality of a nonRING element in priming donor ubiquitin for catalysis by a monomeric E3. Nat Struct Mol Biol. 2013;20(8):982-6.

8. Kassenbrock CK, Anderson SM. Regulation of ubiquitin protein ligase activity in c-Cbl by phosphorylation-induced conformational change and constitutive activation by tyrosine to glutamate point mutations. J Biol Chem. 2004;279(27):28017-27.

9. Kobashigawa Y, Tomitaka A, Kumeta H, Noda NN, Yamaguchi M, Inagaki F. Autoinhibition and phosphorylation-induced activation mechanisms of human cancer and autoimmune disease-related E3 protein Cbl-b. Proc Natl Acad Sci U S A. 2011;108(51):20579-84.

10. Levkowitz G, Waterman H, Ettenberg SA, Katz M, Tsygankov AY, Alroy I, Lavi S, Iwai K, Reiss Y, Ciechanover A, et al. Ubiquitin ligase activity and tyrosine phosphorylation underlie suppression of growth factor signaling by c-Cbl/Sli-1. Mol Cell. 1999;4(6):1029-40.

11. Ryan PE, Sivadasan-Nair N, Nau MM, Nicholas S, Lipkowitz S. The N terminus of $\mathrm{Cbl}-\mathrm{c}$ regulates ubiquitin ligase activity by modulating affinity for the ubiquitin-conjugating enzyme. J Biol Chem. 2010;285(31):23687-98.

12. Schmidt $\mathrm{MH}$, Dikic I. The Cbl interactome and its functions. Nat Rev Mol Cell Biol. 2005;6(12):907-18.

13. Peschard P, Kozlov G, Lin T, Mirza IA, Berghuis AM, Lipkowitz S, Park M, Gehring K. Structural basis for ubiquitin-mediated dimerization and activation of the ubiquitin protein ligase Cbl-b. Mol Cell. 2007;27(3):474-85.

14. Kozlov G, Peschard P, Zimmerman B, Lin T, Moldoveanu T, Mansur-Azzam N, Gehring K, Park M. Structural basis for UBA-mediated dimerization of c-Cbl ubiquitin ligase. J Biol Chem. 2007;282(37):27547-55.

15. Kang JM, Park S, Kim SJ, Hong HY, Jeong J, Kim HS, Kim SJ. CBL enhances breast tumor formation by inhibiting tumor suppressive activity of TGF-beta signaling. Oncogene. 2012;31(50):5123-31.

16. Knight JF, Shepherd CJ, Rizzo S, Brewer D, Jhavar S, Dodson AR, Cooper CS, Eeles R, Falconer A, Kovacs G, et al. TEAD1 and c-Cbl are novel prostate basal cell markers that correlate with poor clinical outcome in prostate cancer. Br J Cancer. 2008;99(11):1849-58.

17. Kales SC, Ryan PE, Nau MM, Lipkowitz S. Cbl and human myeloid neoplasms: the Cbl oncogene comes of age. Cancer Res. 2010;70(12):4789-94.

18. Tan YH, Krishnaswamy S, Nandi S, Kanteti R, Vora S, Onel K, Hasina R, Lo FY, El-Hashani E, Cervantes G, et al. CBL is frequently altered in lung cancers: its relationship to mutations in MET and EGFR tyrosine kinases. PLOS One. 2010;5(1):e8972.

19. Sanada M, Suzuki T, Shih LY, Otsu M, Kato M, Yamazaki S, Tamura A, Honda H, Sakata-Yanagimoto M, Kumano K, et al. Gain-of-function of mutated C-CBL tumour suppressor in myeloid neoplasms. Nature. 2009;460(7257):904-8.

20. Niemeyer CM, Kang MW, Shin DH, Furlan I, Erlacher M, Bunin NJ, Bunda S, Finklestein JZ, Sakamoto KM, Gorr TA, et al. Germline CBL mutations cause developmental abnormalities and predispose to juvenile myelomonocytic leukemia. Nat Genet. 2009;42:794-800. 
21. Thien CB, Walker F, Langdon WY. RING finger mutations that abolish c-Cbldirected polyubiquitination and downregulation of the EGF receptor are insufficient for cell transformation. Mol Cell. 2001;7(2):355-65.

22. Andoniou CE, Thien CB, Langdon WY. Tumour induction by activated abl involves tyrosine phosphorylation of the product of the cbl oncogene. EMBO J. 1994;13(19):4515-23.

23. Dou H, Buetow L, Sibbet GJ, Cameron K, Huang DT. BIRC7-E2 ubiquitin conjugate structure reveals the mechanism of ubiquitin transfer by a RING dimer. Nat Struct Mol Biol. 2012;19(9):876-83.

24. Receveur-Brechot V, Durand D. How random are intrinsically disordered proteins? A small angle scattering perspective. Curr Protein Pept Sci. 2012;13(1):55-75.

25. Panjkovich A, Svergun DI. Deciphering conformational transitions of proteins by small angle $X$-ray scattering and normal mode analysis. Phys Chem Chem Phys. 2016;18(8):5707-19.

26. Skehan P, Storeng R, Scudiero D, Monks A, McMahon J, Vistica D, Warren JT, Bokesch H, Kenney S, Boyd MR. New colorimetric cytotoxicity assay for anticancer-drug screening. J Natl Cancer Inst. 1990;82(13):1107-12.

27. Vichai V, Kirtikara K. Sulforhodamine B colorimetric assay for cytotoxicity screening. Nat Protoc. 2006;1(3):1112-6.

28. Duda DM, Borg LA, Scott DC, Hunt HW, Hammel M, Schulman BA. Structural insights into NEDD8 activation of cullin-RING ligases: conformational control of conjugation. Cell. 2008;134(6):995-1006.

29. Kabsch W. Xds. Acta Crystallogr D Biol Crystallogr. 2010;66(Pt 2):125-32.

30. Winn MD, Ballard CC, Cowtan KD, Dodson EJ, Emsley P, Evans PR, Keegan RM, Krissinel EB, Leslie AG, McCoy A, et al. Overview of the CCP4 suite and current developments. Acta Crystallogr D Biol Crystallogr. 2011;67(Pt 4):235-42.

31. Emsley P, Lohkamp B, Scott WG, Cowtan K. Features and development of Coot. Acta Crystallogr D Biol Crystallogr. 2010;66(Pt 4):486-501.

32. Adams PD, Afonine PV, Bunkoczi G, Chen VB, Davis IW, Echols N, Headd JJ, Hung LW, Kapral GJ, Grosse-Kunstleve RW, et al. PHENIX: a comprehensive Python-based system for macromolecular structure solution. Acta Crystallogr D Biol Crystallogr. 2010;66(Pt 2):213-21.

33. Morgenstern JP, Land $H$. Advanced mammalian gene transfer: high titre retroviral vectors with multiple drug selection markers and a complementary helper-free packaging cell line. Nucleic Acids Res. 1990;18(12):3587-96.

34. Round AR, Franke D, Moritz S, Huchler R, Fritsche M, Malthan D, Klaering R, Svergun DI, Roessle M. Automated sample-changing robot for solution scattering experiments at the EMBL Hamburg SAXS station X33. J Appl Crystallogr. 2008;41:913-7.

35. Franke D, Kikhney AG, Svergun DI. Automated acquisition and analysis of small angle X-ray scattering data. Nucl Instrum Methods A. 2012;689:52-9.

36. Petoukhov MV, Franke D, Shkumatov AV, Tria G, Kikhney AG, Gajda M, Gorba C, Mertens HDT, Konarev PV, Svergun DI. New developments in the ATSAS program package for small-angle scattering data analysis. J Appl Crystallogr. 2012:45:342-50.

37. Konarev PV, Volkov W, Sokolova AV, Koch MHJ, Svergun DI. PRIMUS: a Windows PC-based system for small-angle scattering data analysis. J Appl Crystallogr. 2003;36:1277-82.

38. Guinier A. La diffraction des rayons $X$ aux tres petits angles; application a l'etude de phenomenes ultramicroscopiques. Ann Phys (Paris). 1939;12:161-237.

39. Svergun DI. Determination of the regularization parameter in indirecttransform methods using perceptual criteria. J Appl Crystallogr. 1992;25:495-503.

40. Glatter O, Kratky O, editors. Small angle x-ray scattering. London: Academic; 1982.

41. Durand D, Vives C, Cannella D, Perez J, Pebay-Peyroula E, Vachette P, Fieschi F. NADPH oxidase activator p67(phox) behaves in solution as a multidomain protein with semi-flexible linkers. J Struct Biol. 2010;169(1):45-53.

42. Franke D, Svergun DI. DAMMIF, a program for rapid ab-initio shape determination in small-angle scattering. J Appl Crystallogr. 2009;42:342-6.

43. Volkov W, Svergun DI. Uniqueness of ab initio shape determination in small-angle scattering. J Appl Crystallogr. 2003;36:860-4.

44. Kozin MB, Svergun DI. Automated matching of high- and low-resolution structural models. J Appl Crystallogr. 2001;34:33-41.

45. Tria G, Mertens HD, Kachala M, Svergun DI. Advanced ensemble modelling of flexible macromolecules using $X$-ray solution scattering. IUCrJ. 2015;2(Pt 2):207-17.
46. Bernado P, Mylonas E, Petoukhov MV, Blackledge M, Svergun DI. Structural characterization of flexible proteins using small-angle X-ray scattering. J Am Chem Soc. 2007;129(17):5656-64.

47. Svergun D, Barberato C, Koch MHJ. CRYSOL - A program to evaluate x-ray solution scattering of biological macromolecules from atomic coordinates. J Appl Crystallogr. 1995;28:768-73.

\section{Submit your next manuscript to BioMed Central and we will help you at every step:}

- We accept pre-submission inquiries

- Our selector tool helps you to find the most relevant journal

- We provide round the clock customer support

- Convenient online submission

- Thorough peer review

- Inclusion in PubMed and all major indexing services

- Maximum visibility for your research

Submit your manuscript at www.biomedcentral.com/submit
Biomed Central 